\title{
First record of Coenosia attenuata Stein (Diptera, Muscidae) from Chile, with biological notes
}

\author{
Márcia S. Couri ${ }^{1} \&$ Claudio Salas ${ }^{2}$
}

${ }^{1}$ Museu Nacional, Rio de Janeiro, Departamento de Entomologia, 20940-040 Rio de Janeiro-RJ, Brazil. Fellowship CNPq mcouri@terra.com.br
${ }^{2}$ Instituto de Investigaciones Agropecuarias, Centro Regional de Investigación Intihuasi, Casilla 36-B, La Serena, Chile. csalas@inia.cl

\begin{abstract}
First record of Coenosia attenuata Stein (Diptera, Muscidae) from Chile, with biological notes. Coenosia Meigen (Muscidae, Coenosiinae) species are known as predators of other insects and play an important role as potential biocontrol agents. Six species of Coenosia have been recorded in Europe preying on insects pests, one of them is Coenosia attenuata Stein. This species was recently recorded from the Neotropical Region and is herein recorded for the first time to Chile. Biological notes were included.
\end{abstract}

KEYWORDS. Chile; Coenosiinae; first record; hunter fly.

RESUMO. Novo registro de Coenosia attenuata Stein (Diptera, Muscidae) no Chile com notas biológicas. As espécies de Coenosia Meigen (Muscidae, Coenosiinae) são conhecidas predadoras de outros insetos, apresentando um papel importante como potenciais agentes de controle biológico. Seis espécies de Coenosia têm sido registradas na Europa predando insetos praga, uma delas é Coenosia attenuata Stein. Esta espécie foi recentemente registrada na Região Neotropical e é aqui registrada pela primeira vez no Chile. Notas biológicas são incluídas.

PALAVRAS-CHAVE. Chile; Coenosiinae; mosca-caçadora; primeiro registro.

Coenosia Meigen (Muscidae) is a Coenosiinae genus widespread in all regions, known as predators of other insects, both on the larval and adult stages. Because of its predacious habits Coenosia species play an important role as potential biocontrol agents. Six species of Coenosia - C. atra Meigen, 1830; C. attenuata Stein, 1902; C. humilis Meigen, 1826; C. strigipes Stein, 1916; C. tigrina Fabricius, 1775 and $C$. testacea Robineau-Desvoidy, 1830 - have been recorded in Europe as members of the "greenhouse predator community", preying on white flies, black fungus gnats and leaf-mining flies (Kühne 2000). Within 39 Neotropical species, 14 occur on Chile (Carvalho et al. 2005). This communication records a new predacious Coenosia to Chile and gives some biological notes on its behavior.

The collections of samples analyzed were carried out at the Vicuña Experimental Centre $\left(26^{\circ} 30^{\prime} \mathrm{S}, 70^{\circ} 41^{\prime} \mathrm{W}\right)$ and Pan de Azúcar Experimental Farm (30 $\left.41^{\prime} \mathrm{S}, 71^{\circ} 14^{\prime} \mathrm{W}\right)$ both located in the Elqui Province, Coquimbo Region and belonging to the Agricultural Research Institute, Intihuasi Research Regional Centre. Numerous hunter flies samples were found in blueberries (Vaccinium corymbosum L.) grown at the Vicuña Experimental Centre, and in melons grown in greenhouses at the Pan de Azúcar Experimental Farm. The color photos of male and female heads were made using a Leica DFC 420 camera and Syncroscopy Auto-Montage with a Leica MZ16 microscope.

The material collected was identified as Coenosia attenuata Stein, herein recorded for the first time to Chile.
This is a native species to the Old World (Southern Europe) widespread throughout Europe, Asia, Africa and Australia. Only recently the species was firstly recorded in the New World, in South America (Ecuador and Peru) by MartinezSanchez et al. (2002). And, more recently, Pérez (2006) first reported it in horticultural greenhouse crops in the Bogotá Plateau (Colombia). The author gave a morphological description of adult male and female.

In North America, Hoebeke et al. (2003) first reported C. attennuata to North America based on collections from the USA and Canada, where adult flies were collected from commercial greenhouses in counties of New York State and Ontario Province. The material was collected in 2002 but $C$. attenuata was first noticed in October 1999 in a commercial greenhouse in New York. Other two predacious species, $C$. tigrina and C. humilis, are known from North America, both presumably introduced in the early mid 1800s (Hoebeke et al. 2003).

C. attenuata as well as other species of Coenosia has shown promise as a biological control agent of fungus gnats, shore flies, and other common greenhouse pests (Hoebeke et al. 2003). In colder climates, this fly is known as a very effective predator of various insects and is usually seen in greenhouses attacking pests. It is widely known under the name "killer fly" or "hunter fly" as a potential biological control agent against some plant and other pests (Cock 1993; Gerling et al. 2001; Parrela 2008; among others). Hoebeke et al. (2003) redescribed the species and also presented a 

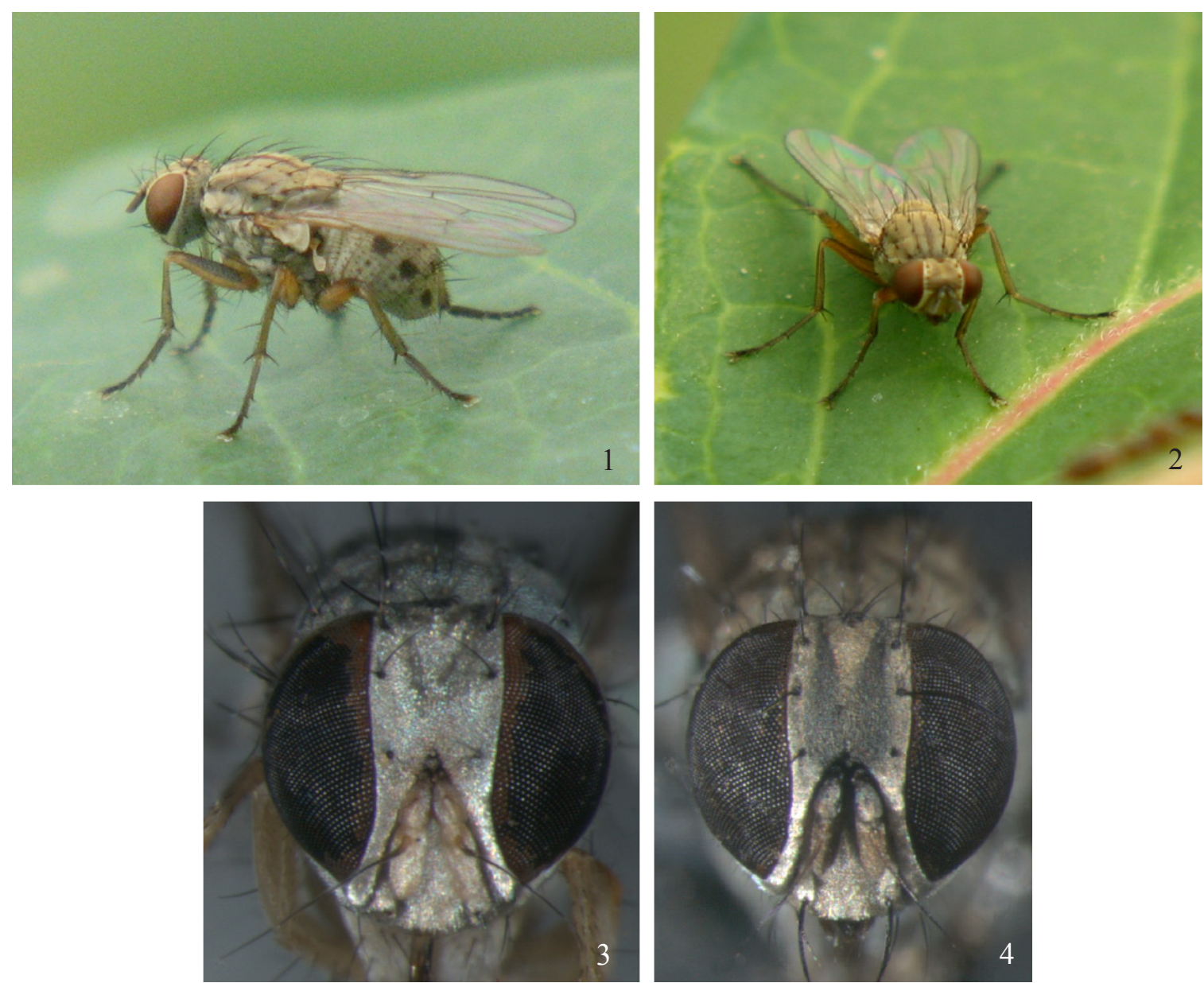

Figs. 1-4. Coenosia attenuata Stein. 1-2. Adult female; 3. Male, head, frontal view; 4. Female, head, frontal view

summary of the available European literature on its biology and habits.

The fly is small, about $2.5-4.0 \mathrm{~mm}$ in length (male smaller than females), brownish grey in ground color, with frons parallel sided in both sexes (male dichoptic); legs yellow in male and black in female. Males have a strong silvery-white frontal vitta, face, parafacial and fronto-orbital plate (Fig. 3). In females these areas are brownish, with very few pollinosity, contrasting with the golden pollinosity of the ocellar triangle, seen under certain lights (Fig 2.).

The specimens of $C$. attenuata collected in the Vicuña area were found predating black fungus gnats flies (Sciaridae, Diptera) on blueberries plants grown in pots. On the other hand, the specimens collected in the Pan de Azúcar area were found predating greenhouse adult white flies (Trialeurodes vaporariorum W., Aleyrodidae-Hemiptera) and leaft mining flies (Liriomyza hudibrensis B, Agromyzidae-Diptera) on melon plants grown in greenhouses.

Acknowledgments. MSC would like to thank to two Brazilian agencies, CNPq (process number 301301/2007-7) and FAPERJ (process number E-26/171.281/2006) for the support to her project. We thank to Leandro Silva Barbosa (Museu Nacional, UFRJ) for the color photographs of the flies heads.

\section{REFERENCES}

Carvalho C. J. B. de; M. S. Couri; A. C. Pont; D. Pamplona \& S. M. Lopes. 2005. A Catalogue of the Muscidae (Diptera) of the Neotropical Region. Zootaxa 860: 1-282.

Cock, M. J. W. 1993. Bemisia tabaci an update 1986-1992 on the cotton whitefly with an annotated bibliography. Ascot, $C A B$ International Institute of Biological Control, $78 \mathrm{p}$.

Gerling, D.; O. Alomar \& J. Arn. 2001. Biological control of Bemisia tabaci using predators and parasitoids. Protection 20: 779-799.

Hoebeke, E. R.; E. J. Sensenbach; J. P. Sanderson \& S. P. Wraight. 2003. First Report of Coenosia attenuata Stein (Diptera: Muscidae), and Old World "Hunter Fly" in North America. Proccedings of the Entomological Society of Washington 105: 769-775.

Kühne, S. 2000. Räuberische Fliegen der Gattung Coenosia Meigen, 1826 (Diptera: Muscidae) und die Möglichkeit ihres Einsatzes bei der biologischen Schädlingsbekämpfung. Studia Dipterologica 9: 78 p.

Martinez-Sanchez, A.; M. A. Marcos-Garcia \& A. C. Pont. 2002. Coenosia attenuata Stein, 1903 (Diptera, Muscidae) nueva especie para la fauna neotropical. Bollettino di Zoologia Agraria edi Bachicoltura 34: 269272.

Parrela, M. P. 2008. Biological control in protected culture: will it continue to expand? Phytoparasitica 3: 3-6.

Pérez, M. M. 2006. Estudio de la morfología externa de los adultos de la mosca cazadora Coenosia attenuata Stein, 1903 (Diptera: Muscidae), y primer reporte para Colombia. Revista de la Facultad de Ciencias Básicas 2: 67-87. 